\title{
Unit Dose Box
}

National Cancer Institute

\section{Source}

National Cancer Institute. Unit Dose Box. NCI Thesaurus. Code C43179.

A box that contains a single dose of a non-parenteral drug product. [Note: Boxes that contain 100 unit dose blister packs should be classified under blister pack, since this is the immediate container into which the dosage form is placed.] 